\title{
Effects of unilateral or bilateral superior ovarian nerve section in prepubertal rats on the ovulatory response to gonadotrophin administration
}

\author{
L Morales, R Chávez, M E Ayala and R Domínguez \\ Biology of Reproduction Research Unit, Laboratory of Physiology of Reproduction, Facultad de Estudios Superiores Zaragoza, UNAM AP 9-020, CP 15000, \\ México, D.F., México \\ (Requests for offprints should be addressed to L Morales)
}

\begin{abstract}
The modulating effects of ovarian innervation reaching the ovary through the suspensory ovarian nerve on the reactivity of the ovaries to gonadotrophins were analysed. Juvenile rats (32 days old), with or without unilateral or bilateral section of the superior ovarian nerve, were injected with 8 iu of pregnant mare serum gonadotrophin (PMSG), 10 iu of human chorionic gonadotrophin (hCG) or with 8 iu of PMSG followed 56 h later with 10 iu of hCG. Treatments were given immediately after surgery or 4 days later, and the rats were killed on the day of first vaginal oestrus. In rats with unilateral section, treatment with PMSG did not induce full ovulatory response by the denervated ovary whether the treatment was applied immediately or 4 days after surgery $(0 / 11$ rats treated immediately ovulated vs 5/5 (sham) and 11/12 (control, $P<0 \cdot 05$ Fisher's exact probability test), and 4/19 did when treatment was done 4 days after surgery vs $8 / 10$ (sham) and $11 / 12$ (control, $P<0 \cdot 05$ ). The rats with bilateral section receiving the same hormonal treatment, PMSG administration, ovulated. The number of ova shed by the left ovary was similar to those of the control, while the right ovary released fewer ova. Stimulation with hCG immediately after unilateral section did not induce ovulation in normal or denervated ovary. When the treatment was applied 4 days after surgery, ovulation was observed only in the innervated ovary. In the rats with bilateral section, hCG injection induced ovulation in both ovaries. In those rats with unilateral section of the superior ovarian nerve, the treatment with PMSG+hCG given immediately after surgery resulted in a compensatory ovulation by the innervated ovary (the number of ova shed/ovulating
\end{abstract}

animal was significantly higher than those released by control or sham-operated animals: left section, number of ova shed by the right ovary $7 \cdot 6 \pm 0 \cdot 3$ vs $5 \cdot 5 \pm 0 \cdot 8$ and $4.9 \pm 1$ respectively, $P<0 \cdot 05$; right section, number of ova shed by the left ovary $10 \cdot 2 \pm 0 \cdot 6$ vs $4 \cdot 4 \pm 1 \cdot 1$ and $7 \cdot 0 \pm 0 \cdot 9, P<0 \cdot 05)$, while the denervated one showed a lower ovulation rate as well as a smaller number of ova shed than those by the control animals. When the hormonal replacement was given 4 days after surgery, such compensatory ovulation was observed in the left ovary of those rats with a section of the right nerve $(14 \cdot 3 \pm 2 \cdot 6$ vs $4 \cdot 4 \pm 1 \cdot 1$ and $6 \cdot 5 \pm 1 \cdot 1, P<0 \cdot 05)$. When the PMSG+hCG treatment was applied to animals with bilateral section of the superior ovarian nerve, the ovulation rate by the right ovary was significantly lower than in control and sham-operated treated animals (2/10 vs $11 / 11$ and $6 / 7, P<0 \cdot 05)$. Because the ovaries receive innervation through the superior ovarian nerve, the ovarian plexus and the vagus nerve, the results obtained in unilateral denervated animals suggest that the innervation of the ovary via the superior ovarian nerve regulates in a stimulatory way the effects of gonadotrophin resulting in ovulation. The ovulation induced by hormonal treatment of rats with bilateral section of the superior ovarian nerve suggests that the effects of bilateral section on ovulation are not the addition of the effects of left and right denervation, implying the existence of a modulatory effect in gonadotrophin action on ovulation via other neural pathways.

Journal of Endocrinology (1998) 158, 213-219

\section{Introduction}

The evidence obtained from pharmacological or surgical denervation suggests that ovarian innervation participates in the regulation of ovarian functions. The main neural information arriving at the ovaries is through the superior ovarian nerve, ovarian plexus and vagus nerve (Burden 1978, Lawrence \& Burden 1980).

Peripheral sympathetic denervation, induced by chronic guanethidine injection into prepubertal rats, results in a marked accumulation of small antral follicles and a relative paucity of large follicles (Lara et al. 1990), as well as an 
increase in the number of ova shed by ovulating animals (Flores et al. 1990). The sympathetic denervation produced by bilateral section of the superior ovarian nerve results in an acute decrease in serum levels of progesterone (Erskine et al. 1988) or oestradiol (Aguado \& Ojeda 1984). This evidence supports the idea that hormonal control of ovarian functions (hormonal secretion and ovulation) is modulated by ovarian innervation.

We have previously shown that the effects of unilateral or bilateral ovarian denervation on ovulation are different. While bilateral section of the superior ovarian nerve performed in prepubertal and adult rats did not modify the number of ovulating rats (ovulation rate), nor the number of ova shed, unilateral section resulted in a diminution of the ovulation rate and the number of ova shed by the denervated ovary (Chávez et al. 1991, Morales et al. 1993). These results suggest that ovarian innervation through the superior ovarian nerve modulates the responsiveness of the ovarian compartments to gonadotrophins, in a stimulatory and asymmetrical manner (Chávez \& Domínguez 1994, Domínguez et al. 1998).

Our objective was to analyse whether ovarian innervation reaching the ovary through the superior ovarian nerve modulates the reactivity of the ovary to gonadotrophins in a stimulatory way, and to compare the effects on ovulation of gonadotrophin administration to prepubertal rats with and without unilateral or bilateral section of the superior ovarian nerve. For that purpose, the animals were stimulated with pregnant mare serum gonadotrophin (PMSG) to induce follicular growth and oestrogen secretion or with human chorionic gonadotrophin (hCG) to induce oestrogen secretion without an initial acceleration of the follicular development. Both paradigms need endogenous luteinising hormone $(\mathrm{LH})$ release to induce ovulation (D'Albora et al. 1974, Greenwald \& Roy 1994). To bypass the neuroendocrine endogenous mechanisms regulating LH secretion, PMSG was injected, followed $56 \mathrm{~h}$ later by hCG.

\section{Materials and Methods}

\section{Animal surgery and hormone treatment}

Thirty-two-day old CIIZ-V strain female rats from our breeding stock were kept under conditions of controlled lighting (lights on from 0500 to $1900 \mathrm{~h}$ ). The animals were kept in group cages (six rats per cage), with free access to food and tap water. All surgery was under ether anaesthesia. Groups of untouched-, sham-operated- and denervated-gonadotrophin treated rats were processed at the same time. Gonadotrophins were diluted in saline, and $0.5 \mathrm{ml}$ was injected subcutaneously. Rats were inspected daily for vaginal opening, and once it occurred vaginal smears were obtained daily. On the morning of the day of the first vaginal oestrus, all animals were killed by bleeding under ether anaesthesia.
The animals were allotted at random to one of three groups.

Sham-operated group Forty-five rats were anaesthetised, laparotomised and the wound sealed. Three groups of animals were treated immediately after surgery with 8 iu of PMSG (Sigma Chemical Co., St Louis, MO, USA) (five rats); or 10 iu of hCG (Sigma) (five rats); or 8 iu of PMSG followed $56 \mathrm{~h}$ later by $10 \mathrm{iu}$ of hCG (eight rats). Three other groups of sham-operated animals were left untouched for 3 days, and on day 4 they were treated with gonadotrophins in the same described sequence (ten treated with PMSG, ten with hCG and seven with PMSG+hCG).

Denervated animals One hundred and fifty-seven rats were used. A midline incision was made to provide access to the suspensory ligament (left, right or both) containing the superior ovarian nerve. It was then isolated from the surrounding tissue, and the nerve was sectioned as previously described (Chávez et al. 1991, Morales et al. 1993). When a bilateral section was performed, the first nerve sectioned was always the left one. All the animals were injected with PMSG, hCG or PMSG+hCG, immediately or on day 4 after surgery.

Control untouched group Thirty-six-day-old rats were injected with PMSG (24 animals), hCG (14 rats) or PMSG+hCG (22 animals).

\section{Autopsy procedure}

The animals were killed by an ether overdose. At autopsy, the right and left oviducts were dissected and the number of ova present was counted with the aid of a dissecting microscope. Ovaries and uterus were removed and weighed using a precision balance. The ovaries from non-ovulating rats were fixed in Bouin's fluid, embedded in paraffin, serial sectioned, stained with haematoxylineosin and inspected for the presence of fresh corpora lutea.

\section{Statistical analysis}

Data on the weight of the ovaries and uterus were analysed by multivariate analysis of variance (MANOVA) (for each time when the animals were treated, immediately after surgery and 4 days later, the independent variables were group and hormonal treatments), followed by Tukey's test. Ovulation rate (number of ovulating animals/number of treated one) (Chávez \& Domínguez 1994) was analysed by Fisher's exact probability test or the Chi square test; number of ova shed/ovulating animal by the KruskalWallis test followed by a Mann-Whitney U test. A $P$ value of less than $0 \cdot 05$ was considered significant. 
Table 1 Ovulation rate (number of ovulating/number of treated) and mean \pm S.E.M. number of ova shed in animals with unilateral or bilateral section of the superior ovarian nerve performed on 32-day-old rats treated with 8 iu PMSG immediately or 4 days later. Animals were autopsied at the first day of vaginal oestrus

\begin{tabular}{|c|c|c|c|c|c|c|c|c|}
\hline & \multicolumn{4}{|c|}{ Immediately after surgery } & \multicolumn{4}{|c|}{ Four days later } \\
\hline & \multicolumn{2}{|c|}{ Ovulation rate } & \multicolumn{2}{|c|}{ Number of ova shed } & \multicolumn{2}{|c|}{ Ovulation rate } & \multicolumn{2}{|c|}{ Number of ova shed } \\
\hline & Left & Right & Left & Right & Left & Right & Left & Right \\
\hline \multicolumn{9}{|l|}{ Group } \\
\hline Control & $11 / 12$ & $11 / 12$ & $6 \cdot 6 \pm 0.9$ & $6 \cdot 5 \pm 1 \cdot 2$ & $11 / 12$ & $11 / 12$ & $6 \cdot 6 \pm 0 \cdot 9$ & $6 \cdot 5 \pm 1 \cdot 2$ \\
\hline Sham & $4 / 5$ & $5 / 5$ & $5 \cdot 0 \pm 1 \cdot 3$ & $5 \cdot 8 \pm 0 \cdot 4$ & $8 / 10$ & $8 / 10$ & $4 \cdot 7 \pm 0 \cdot 8$ & $5 \cdot 9 \pm 0.9$ \\
\hline Left section & $0 / 5$ & $1 / 5 \dagger^{*}$ & 0 & 7 & $2 / 9 \dagger^{*}$ & $9 / 9$ & 3,5 & $5 \cdot 7 \pm 0 \cdot 7$ \\
\hline Right section & $4 / 6$ & $0 / 6$ & $3 \cdot 8 \pm 0.5 \dagger$ & 0 & $9 / 10$ & $2 / 10 \dagger^{*}$ & $6 \cdot 1 \pm 0 \cdot 8$ & 1,2 \\
\hline Bilateral section & $11 / 12$ & $6 / 12 \dagger^{*}$ & $5 \cdot 8 \pm 0 \cdot 6$ & $2 \cdot 8 \pm 0 \cdot 9 \dagger^{*}$ & $7 / 10$ & $5 / 10 \dagger$ & $7 \cdot 5 \pm 2 \cdot 2$ & $3 \cdot 4 \pm 1 \cdot 3$ \\
\hline
\end{tabular}

$\dagger P<0.05$ vs control group (ovulation rate by Chi square test; number of ova shed by Kruskal-Wallis test).

${ }^{*} P<0 \cdot 05$ vs sham group (ovulation rate by Chi square test; number of ova shed by Kruskal-Wallis test).

Table 2 Mean \pm S.E.M. of the weight of ovaries ( $\mathrm{mg} / 100 \mathrm{~g}$ body weight) in animals with unilateral or bilateral section of the superior ovarian nerve performed on 32-day-old rats, treated with 8 iu PMSG, 10 iu hCG or PMSG plus hCG immediately or 4 days later. Animals were autopsied on the first day of vaginal oestrus

\begin{tabular}{|c|c|c|c|c|c|c|}
\hline & \multicolumn{3}{|c|}{ Immediately after surgery } & \multicolumn{3}{|c|}{ Four days later } \\
\hline & PMSG & hCG & PMSG +hCG & PMSG & hCG & PMSG +hCC \\
\hline \multicolumn{7}{|l|}{ Group } \\
\hline Control & $60 \cdot 8 \pm 4 \cdot 0$ & $37 \cdot 5 \pm 3 \cdot 2$ & $47 \cdot 9 \pm 2 \cdot 1$ & $60 \cdot 8 \pm 4 \cdot 0$ & $37 \cdot 5 \pm 3 \cdot 2$ & $47 \cdot 9 \pm 2 \cdot 1$ \\
\hline Sham & $53 \cdot 2 \pm 7 \cdot 3$ & $65 \cdot 6 \pm 4 \cdot 8 \dagger$ & $65 \cdot 3 \pm 3 \cdot 4 \dagger$ & $41 \cdot 7 \pm 3 \cdot 6 \dagger$ & $47 \cdot 9 \pm 1 \cdot 5 \dagger$ & $71 \cdot 4 \pm 2 \cdot 6 \dagger$ \\
\hline Left section & $42 \cdot 3 \pm 3 \cdot 2 \dagger$ & $61 \cdot 7 \pm 3 \cdot 9 \dagger$ & $73 \cdot 1 \pm 2 \cdot 1 \dagger$ & $56 \cdot 6 \pm 5 \cdot 7$ & $50 \cdot 2 \pm 2 \cdot 4 \dagger$ & $57 \cdot 9 \pm 5 \cdot 3$ \\
\hline Right section & $41 \cdot 9 \pm 5 \cdot 7 \dagger$ & $55 \cdot 7 \pm 4 \cdot 3 \dagger$ & $60 \cdot 2 \pm 2 \cdot 4 \dagger$ & $50 \cdot 8 \pm 6 \cdot 7$ & $42 \cdot 8 \pm 1 \cdot 3$ & $66 \cdot 6 \pm 9 \cdot 4$ \\
\hline Bilateral section & $67 \cdot 8 \pm 2 \cdot 1$ & $59 \cdot 8 \pm 4 \cdot 0 \dagger$ & $72 \cdot 4 \pm 4 \cdot 0 \dagger$ & $55 \cdot 6 \pm 2 \cdot 8^{*}$ & $55 \cdot 1 \pm 2 \cdot 9 \dagger^{*}$ & $60 \cdot 6 \pm 6 \cdot 2$ \\
\hline
\end{tabular}

$\dagger P<0 \cdot 05$ vs control group (MANOVA).

${ }^{*} P<0 \cdot 05$ vs sham group (MANOVA).

\section{Results}

Vaginal opening occurred $72 \mathrm{~h}$ after the beginning of the hormone stimulation in all rats (control+PMSG 24/ 24, control+hCG 14/14, control+PMSG+hCG 22/22; sham+PMSG 15/15, sham+hCG 15/15, sham+PMSG+ hCG 15/15; denervated+PMSG 52/52, denervated+ hCG 48/48, denervated+PMSG+hCG 57/57), and all the animals presented vaginal oestrus.

\section{Effects of PMSG injection}

Immediately after surgery Eleven out of 12 untouched control animals and five out of five sham-operated rats treated with PMSG, ovulated. Differences in the number of ova shed by ovulating animals were not observed $(13.0 \pm 1.96$ in untouched control animals, and $11.0 \pm$ 0.63 in sham-operated (NS, Mann-Whitney U test).

In those rats with section of the left superior ovarian nerve, a decrease in the ovulation rate occurred in both ovaries. None of the non-ovulating animals presented fresh corpora lutea in the ovaries. In the rats with section of the right superior ovarian nerve, a diminution in ovulation rate by the denervated ovary was observed, while the number of ova shed decreased in both ovaries. The ovulation rate and number of ova shed by the left ovary were not affected by bilateral section of the superior ovarian nerve, while both parameters decreased in the right ovary (Table 1).

The weight of the ovaries in rats with unilateral section of the superior ovarian nerve was significantly lower than in untouched animals (Table 2). Such differences only occurred in the weight of the left ovary (left section: $19 \cdot 4 \pm 2.6 \mathrm{mg} / 100 \mathrm{~g}$ body weight; right section: $17 \cdot 9 \pm 1 \cdot 8$ vs $35 \cdot 3 \pm 4 \cdot 8, P<0 \cdot 05$ MANOVA followed by Tukey's test).

The weight of the uterus in the sham-operated group was significantly lower than in untouched control animals $(136.7 \pm 7 \cdot 3 \mathrm{mg} / 100 \mathrm{~g}$ body weight vs $167 \cdot 5 \pm 4 \cdot 1$ $P<0 \cdot 05)$. Significant differences in the uterine weight between sham-operated and rats with unilateral or bilateral section of the superior ovarian nerve were not observed.

Four days after surgery Sham-operated animals ovulated in a similar way to controls. In rats with unilateral section of the superior ovarian nerve, the denervated ovary did not respond to PMSG treatment, while the innervated 
Table 3 Ovulation rate (number of ovulating/number of treated) and mean \pm S.E.M. number of ova shed in animals with unilateral or bilateral section of the superior ovarian nerve performed on 32-day-old rats treated with 10 iu hCG immediately or 4 days later. Animals were autopsied at the first day of vaginal oestrus

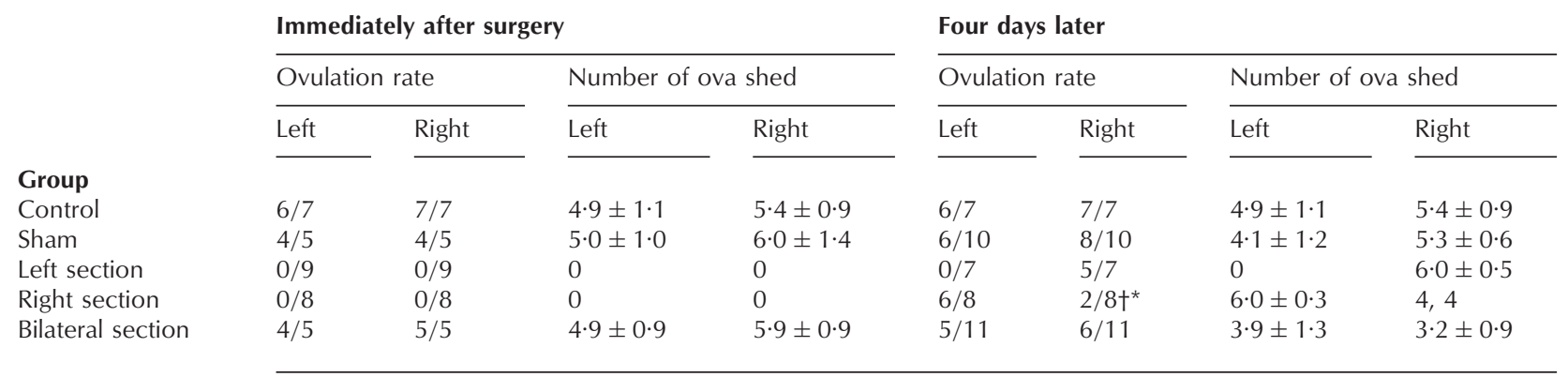

gonad showed a similar response to that of sham-operated ones. In rats with bilateral section of the nerve, the number of ova shed by both ovaries was similar to that of sham-operated animals, while the ovulation rate by the right ovary was significantly lower (Table 1 ).

The weight of ovaries of rats with sham operation was lower than in untouched control animals injected with PMSG, but differences were not observed in rats with unilateral or bilateral section of the superior ovarian nerve (Table 2). Differences in the weight of the uterus were not observed.

\section{Effects of hCG injection}

Differences in ovulation rate and number of ova shed between untouched control and sham-operated rats treated with hCG immediately or 4 days after surgery were not observed.

Immediately after surgery The injection of hCG did not induce ovulation in those animals with unilateral section of the superior ovarian nerve, while all the animals with bilateral section did ovulate (Table 3). Fresh corpora lutea were not observed in the ovaries of non-ovulating animals.

The weight of the ovaries of sham-operated rats, and of rats with unilateral or bilateral section of the superior ovarian nerve and injected with hCG, was significantly higher than in untouched control rats (Table 2). Differences in the weight of the uterus were not observed.

Four days after surgery In all animals with section of the left superior ovarian nerve, the denervated ovary did not ovulate, while $71 \%$ of the innervated ovaries ovulated normally. When the animals had a section of the right nerve, hCG treatment induced ovulation in $75 \%$ of the left ovaries and in only $25 \%$ of the right ones. In those animals with bilateral section, hCG administration induced ovu- lation in $55 \%$ of the animals (Table 3). Again, corpora lutea were not observed in the ovaries of non-ovulating animals.

The weight of the ovaries was significantly increased in sham-operated rats and rats with bilateral section, or section of the left nerve and injection of hCG (Table 2).

\section{Effects of PMSG+hCG injection}

Differences were not observed in the ovulation rate and number of ova shed between untouched control and sham-operated rats treated with PMSG and hCG immediately or 4 days after surgery,

Immediately after surgery In those rats with section of the left superior ovarian nerve, the sequential administration of PMSG + hCG induced ovulation in $66 \%$ of the left ovaries, but the number of ova shed was significantly lower than in sham-operated animals. The right ovary in these animals released more ova than did sham-operated ones. When the section was performed in the right ovary, the ovulation rate and number of ova shed by the denervated ovary (right) were significantly lower than in sham-operated animals. When the animals were submitted to bilateral nerve section, the sequential administration of PMSG + hCG elicited an ovulatory response similar to that seen in the sham-operated group (Table 4).

The increase in the ovarian weight induced by PMSG + hCG administration was higher in sham-operated rats and rats with unilateral or bilateral section of the superior ovarian nerve than in untouched control animals (Table 2).

Four days after surgery In those animals with unilateral section of the superior ovarian nerve, the injection of PMSG+hCG did not induce ovulation by the denervated ovary. In those rats with section of the right nerve, the number of ova shed by the left ovary was significantly higher than in sham-operated ones. In rats with bilateral section of the nerve, the hormonal treatment induced 
Table 4 Ovulation rate (number of ovulating/number of treated) and mean \pm S.E.M. number of ova shed in animals with unilateral or bilateral section of the superior ovarian nerve performed on 32-day-old rats treated with 8 iu PMSG plus 10 iu hCG immediately or 4 days later. Animals were autopsied at the first day of vaginal oestrus

\begin{tabular}{|c|c|c|c|c|c|c|c|c|}
\hline & \multicolumn{4}{|c|}{ Immediately after surgery } & \multicolumn{4}{|c|}{ Four days later } \\
\hline & \multicolumn{2}{|c|}{ Ovulation rate } & \multicolumn{2}{|c|}{ Number of ova shed } & \multicolumn{2}{|c|}{ Ovulation rate } & \multicolumn{2}{|c|}{ Number of ova shed } \\
\hline & Left & Right & Left & Right & Left & Right & Left & Right \\
\hline \multicolumn{9}{|l|}{ Group } \\
\hline Control & $10 / 11$ & $11 / 11$ & $4 \cdot 4 \pm 1.1$ & $5 \cdot 5 \pm 0 \cdot 8$ & $10 / 11$ & $11 / 11$ & $4 \cdot 4 \pm 1 \cdot 1$ & $5 \cdot 5 \pm 0 \cdot 8$ \\
\hline Sham & $8 / 8$ & $7 / 8$ & $7 \cdot 0 \pm 0 \cdot 9$ & $4 \cdot 9 \pm 1 \cdot 0$ & $6 / 7$ & $6 / 7$ & $6 \cdot 5 \pm 1 \cdot 1$ & $6 \cdot 2 \pm 0 \cdot 7$ \\
\hline Left section & $6 / 9$ & $9 / 9$ & $1 \cdot 8 \pm 0.5 \dagger^{*}$ & $7 \cdot 6 \pm 0 \cdot 3^{*}$ & $3 / 8 \dagger$ & $6 / 8$ & $2 \cdot 5 \pm 1 \cdot 2^{*}$ & $7 \cdot 2 \pm 0 \cdot 7$ \\
\hline Right section & $12 / 12$ & $3 / 12 \dagger^{*}$ & $10 \cdot 2 \pm 0.6 \dagger^{*}$ & $0 \cdot 8 \pm 0 \cdot 4 \dagger^{*}$ & $8 / 11$ & $0 / 11$ & $14 \cdot 3 \pm 2 \cdot 6 \dagger^{*}$ & 0 \\
\hline Bilateral section & $5 / 7$ & $4 / 7$ & $5 \cdot 5 \pm 1 \cdot 1$ & $5 \cdot 2 \pm 1 \cdot 7$ & $7 / 10$ & $2 / 10 \dagger^{*}$ & $5 \cdot 8 \pm 1 \cdot 7$ & 7,6 \\
\hline
\end{tabular}

$\dagger P<0.05$ vs control group (ovulation rate by Chi square test; number of ova shed by Kruskal-Wallis test).

${ }^{*} P<0.05$ vs sham group (ovulation rate by Chi square test; number of ova shed by Kruskal-Wallis test).

ovulation in $70 \%$ of the left ovaries, but only in $20 \%$ of the right ones (Table 4). As in PMSG- or hCG-treated animals, the ovaries of the non-ovulating animals did not present fresh corpora lutea.

When the ovulatory reactivity of the right and left ovaries in rats with bilateral section of the superior ovarian nerve to different treatments was compared, a significant difference was observed: in PMSG-treated animals (immediately after surgery and 4 days after), the left ovary ovulated in $18 / 22$ rats treated vs the right ovary in $11 / 22$ rats $(P<0 \cdot 05$, Chi square test); when the animals were injected with $\mathrm{PMSG}+\mathrm{hCG}$, the left ovary ovulated in $12 / 17$ rats vs $6 / 17$ for the right one $(P<0 \cdot 01$, Chi square test); such differences were not observed in hCG-treated animals (left ovary ovulated in 9/16 rats vs 11/16 animals by the right ovary, NS).

The increase induced by PMSG $+\mathrm{hCG}$ administration in the weight of the ovaries of rats with uni- or bilateral section of the nerve was similar to that induced in the untouched animals, and it was higher in sham-operated ones (Table 2).

\section{Discussion}

The results obtained in the present study suggest that the innervation reaching the ovary via the superior ovarian nerve regulates, in a stimulatory way, the effects of gonadotrophin, resulting in ovulation. The results obtained by Mayerhofer et al. (1997) suggested that in the ovaries of 2-day-old rats, norepinephrine and vasoactive intestinal polypeptide regulate the synthesis of follicle-stimulating hormone receptors in a stimulatory way, supporting such an interpretation.

Previous reports showed that in the prepubertal rat, the bilateral superior ovarian nerve section provoked a marked decrease in ovarian norepinephrine content (Aguado \& Ojeda 1984, Selstam et al. 1985, Chávez et al. 1994). This decrease was accompanied by an almost 2-fold increase in $\beta$-adrenergic receptor number, while the affinity of receptors was similar in sham-operated rats (Aguado \& Ojeda 1984). A luteinising hormone-releasing hormone content in denervated ovary was also observed by Marchetti et al. (1987). Such a norepinephrine content decrease did not affect spontaneous and induced ovulation, since in the rat with and without gonadotrophin stimulation, the bilateral section of the superior ovarian nerve altered neither the time of vaginal opening, nor that of the first ovulation. These results suggest that sympathetic information which travels along the suspensory ligament does not play an obligatory role in the ovulation process (Aguado \& Ojeda 1984, Selstam et al. 1985). Another possibility is that 'the effects of bilateral section on ovulation are not the addition of the effects of left and right denervation, implying the existence of a modulatory effect in gonadotrophin action on ovulation via other neural pathways' (Morales et al. 1993).

Because, in the animals with bilateral section and administration of PMSG+hCG, the ovulatory response was normal compared with the sham group, we presume that the development of denervation supersensitivity by the increase in $\beta$-adrenergic receptor number (Aguado \& Ojeda 1984) might compensate for the loss of neural input to the ovary. At present, we do not have a satisfactory explanation for the low ovulation rate by the right ovary observed in those rats injected with PMSG+hCG 4 days after bilateral denervation. The differences in the ovulatory response by the left and right ovary in rats with bilateral section of the superior ovarian nerve support our previous statement that the differences in ovulatory ability by the left and right ovary are related to ovarian innervation (Domínguez et al. 1989), because the ovaries are still receiving innervation through the ovarian plexus and the vagus nerve (Burden 1978). Another possibility is the existence of some kind of bloodborne information between the ovaries, as was proposed previously (D'Albora et al. 1992). 
In rats with unilateral section, the sequential injection of PMSG+hCG did not induce normal ovulation by the denervated ovary, while the innervated ovary performed normally or showed superovulation. We can presume that the unilateral section of the superior ovarian nerve results in an ovarian supersensitivity; for which, therefore, the lack of ovulatory response by the denervated ovary cannot be explained in the same way. These results support the idea that there is neural communication between both ovaries (Gerendai et al. 1978, Domínguez et al. 1989, Morales et al. 1993), which would be via multiple pathways. When one of them is severed, the lack of information originating in this ovary induces an inhibitory signal arising from the innervated ovary reaching the partially denervated ovary through one of the other neural pathways. Such an interpretation agrees with the results of Klein et al. (1989) that the stimulation of the superior ovarian nerve results in an electrical signal in the ovarian plexus nerve.

When the animals were treated with PMSG or hCG to induce ovulation, it was necessary that the endogenous neuroendocrine mechanisms regulating the LH preovulatory surge were working normally (Greenwald \& Roy 1994). The lack of, or very low, ovulation by the denervated ovary observed in those animals with unilateral section of the superior ovarian nerve injected with PMSG, supports the interpretation that neural signals reaching the ovary through such a nerve play a role in the regulation of the reactivity of the ovary to gonadotrophins. Because, in the animals with section of the left ovarian nerve or bilateral section (in all animals the left nerve was sectioned first), PMSG did not induce full ovulation, we can presume that such neural signals, provoked in this experiment by cutting the nerve, initiated in the left ovary and sent to the right one, play an inhibitory role on the response of the right ovary to endogenous gonadotrophins, or inhibit the relay of a neural signal to the central nervous system arriving at the hypothalamus, as was proposed previously (Domínguez et al. 1998).

When ovulation was induced by hCG administration 4 days after surgery, the results were similar to those in the animals treated with PMSG. The lack of ovulation response to hCG administration in the denervated ovary of prepubertal rats with unilateral section of the superior ovarian nerve, is similar to the results obtained in adult rats with the same treatment (Chávez et al. 1991).

The differences observed between the response to the injection of PMSG or hCG immediately after surgery in animals with section of the right ovarian superior nerve could be explained by the results of Roth \& Jones (1992) in the lizard, where one ovary is less sensitive to gonadotrophin administration. Another possibility is that such a variation is explained by the differences described in neuronal mechanisms involved in signal transduction for PMSG and hCG (Hsueh et al. 1994).

\section{Acknowledgements}

This work was supported by CONACyT grants ESP-200191 and IN1719, DGAPA IN210893, PUIS and PADEP.

\section{References}

Aguado LI \& Ojeda SR 1984 Prepubertal ovarian function is finely regulated by direct adrenergic influences. Role of noradrenergic innervation. Endocrinology 114 1845-1853.

Burden HW 1978 Ovarian innervation. In The Vertebrate Ovary: Comparative Biology, pp 615-638. Ed. RE Jones. New York: Plenum Press.

Chávez R \& Domínguez R 1994 Participation of the superior ovarian nerve in the regulation of compensatory ovarian hypertrophy: the effects of its section performed on each day of the oestrous cycle. Journal of Endocrinology 140 197-201.

Chávez R, Carrizosa L \& Domínguez R 1991 Effects of superior ovarian nerve on spontaneous and induced ovulation in adult rats. Medical Science Research 19 41-42.

Chávez R, Morales L, González Ma E \& Domínguez R 1994 Ovarian norepinephrine content in prepubertal rats with superior ovarian nerve section: Temporal studies. Medical Science Research $\mathbf{2 2}$ 789-790.

D’Albora H, Carlevaro E, Riboni L, de Los Reyes L, Zipitría D \& Domínguez R 1974 'Advanced puberty' in female guinea pigs treated with human chorionic gonadotropin (HCG) or testosterone enantate (ET) at birth. Hormone Research 5 344-350.

D’Albora H, Cassina MP, Barreiro JP, Sapiro R \& Domínguez R 1992 Differences in follicular growth and ovulation ability in the autografted right and left ovary of hemiovariectomised prepubertal rats. Medical Science Research 20 755-757.

Domínguez R, Cruz ME \& Chávez R 1989 Differences in the ovulatory ability between the right and left ovary related to ovarian innervation. In Growth Factors and the Ovary, pp 321-325. Ed. AM Hirsfield. New York: Plenum Press.

Domínguez R, Cruz ME \& Morán C 1998 Differential effects of ovarian local anesthesia during proestrus, on the ovulation by the right or left ovary, in normal and hemiovariectomized adult rat. Journal of Reproduction and Fertility (In Press).

Erskine MS \& Weaver ChE 1988 The role of ovarian sympathetic innervation in the control of estrous responsiveness in the rat. Hormones and Behavior 22 1-11.

Flores A, Ayala ME \& Domínguez R 1990 Does noradrenergic peripheral innervation have a different role in the regulation of ovulation in the puberal and adult rat? Medical Science Research 18 $817-818$.

Gerendai I, Marchetti B, Mauger S, Roxas MA \& Scapagnini V 1978 Prevention of compensatory ovarian hypertrophy by local treatment of the ovary with 6-hydroxidopamine. Neuroendocrinology 27 272-278.

Greenwald GS \& Roy SK 1994 Follicular development and its control. In The Physiology of Reproduction, 2nd edn, pp 629-724. Eds E Knobil \& JD Neill. New York: Raven Press.

Hsueh AJW, Billig H \& Tsafriri A 1994 Ovarian follicle atresia: A hormonally controlled apoptotic process. Endocrine Reviews 15 707-724.

Klein CM, Ray RH \& Burden HW 1989 Direct electrical stimulation of the superior ovarian nerve in rats causes an increase in neuronal activity in the ipsilateral ovarian plexus nerve. Brain Research 479 194-200.

Lara HE, McDonald JK, Ahmed CE \& Ojeda SR 1990 Guanethidine-mediated destruction of ovarian sympathetic nerves disrupts ovarian development and function in rats. Endocrinology 127 2199-2209. 
Lawrence IE Jr \& Burden HW 1980 The origin of the extrinsic adrenergic innervation to the rat ovary. Anatomical Record 196 51-59.

Marchetti MC, Badr M, Folléa N \& Pelletier G 1987 Ovarian adrenergic nerves directly participate in the control of luteinizing hormone-releasing hormone and adrenergic receptors during puberty: A biochemical and autoradiographic study. Endocrinology 121 219-226.

Mayerhofer A, Dissen GA, Costa ME \& Ojeda SR 1997 A role for neurotransmitters in early follicular development: Induction of functional follicle-stimulating hormone receptors in newly formed follicles of the rat ovary. Endocrinology 138 3320-3329.

Morales L, Chávez R \& Domínguez R 1993 Participation of the superior ovarian nerve in the regulation of ovulation in the prepubertal rat: differential effects of unilateral and bilateral section of the nerve. Medical Science Research 21 15-17.

Roth JJ \& Jones RE 1992 A single ovary of Anolis carolinensis responds more to exogenous gonadotropin if the contralateral ovary is absent. General and Comparative Endocrinology 85 486-492.

Selstam G, Norjavaara E, Tegenfelt T, Lundeberg S, Sandstrom Ch \& Sven-Ake P 1985 Partial denervation of the ovaries by transection of the suspensory ligament does not inhibit ovulation in rats treated with pregnant mare serum gonadotrophin. Anatomical Record 213 392-395

Received 9 January 1998

Revised manuscript received 9 March 1998 Accepted 19 March 1998 